\title{
EFFECTS OF OBSTACLE HEIGHT ON THE CONTROL OF THE BODY CENTER OF MASS MOTION DURING OBSTRUCTED GAIT
}

\author{
Ting-Ming Wang, Hao-Ling Chen, and Tung-Wu Lu*
}

\begin{abstract}
Tripping over obstacles has been reported as one of the most frequent causes of falls in the elderly. Since a successful crossing requires the stability of the body through the control of the motion of the body center of mass (COM), the purpose of this study was to investigate the COM motion when crossing obstacles of different heights. Ten young healthy adults walked and crossed obstacles of heights of $10 \%$, $20 \%$ and $30 \%$ of their leg lengths in a gait laboratory. The COM motions were calculated using data measured from a motion analysis system. It was found that vertical motions of the COM, including position, velocity and acceleration, were all modulated to successfully cross obstacles of different height. All acceleration components of the COM were changed with increased obstacle height, suggesting that different forces from muscle contractions were needed to control COM stability when facing different obstacle heights. These findings may help shed light on further investigation of the motor control strategies of the central nervous system for obstacle crossing and serve as baseline data in the evaluation of the elderly and patients.
\end{abstract}

Key Words: obstructed gait, center of mass, height effects

\section{INTRODUCTION}

Tripping over obstacles has been reported as one of the most frequent causes of falls which account for the majority of deaths related to injury among the elderly (Blake et al., 1988; Campbell et al., 1990; Overstall et al., 1977; Tinetti and Speechley, 1989). A successful and safe obstacle-crossing requires not only sufficient foot clearance of the swing limb but also the stability of the body provided mainly by the stance limb. Many studies have investigated the joint kinematics and kinetics of the locomotor system in young adults during obstacle-crossing (Austin et al., 1999; Begg et al., 1998; Chen and Lu, 2006; Chou and Draganich, 1997; Chou and Draganich, 1998; Chou and Draganich, 1998; Chou et al., 2001; Patla et al., 1991; Patla and Rietdyk, 1993; Patla and Prentice, 1995; Patla et al., 1996; Sparrow et al.,

*Corresponding author. (Tel: 886-2-33653335; Fax: 886-233653335; Email: twlu@ntu.edu.tw)

The authors are with the Institute of Biomedical Engineering, National Taiwan University, Taipei Taiwan 106, R.O.C. and T. M. Wang is currently at Department of Orthopaedic Surgery, National Taiwan University Hospital, Taipei, Taiwan 100, R.O.C.
1996) partly because inappropriate control of the locomotor system may contribute to body imbalance which further leads to tripping over obstacles. Although these studies helped in clarifying the role of the locomotor system during obstacle-crossing, knowledge of the control of the body as a system described by the movement of the center of mass (COM) may provide more direct information on the dynamic stability of the body during this activity, which will be useful for the design of fall-prevention devices and for the planning of programs for the prevention of associated injuries.

The motion of the COM in relation to the base of support (BOS) has been used to represent the balance control of the body (Kuo, 1995; Patla et al., 1990). It is generally believed that a person can maintain balance as long as the projection of the COM is kept within the BOS, as seen during standing (Kuo, 1995; Patla et al., 1990). However, it has been shown that the COM may travel outside the BOS without losing balance during dynamic tasks such as locomotion (Winter, 1995) and sit-to-stand (Pai et al., 1994). Therefore, whether the projection of the COM is within the BOS is not sufficient to describe the 
stability in these situations. Center of pressure (COP) and velocity of the COM have been used to describe the dynamic stability during activities of daily living (Collins and Luca, 1993; Goldie et al., 1989; Pai and Patton, 1997). Pai and Patton (Pai and Patton, 1997) used COM velocity-position to demonstrate the dynamic stability in the anterioposterior (A/P) direction during locomotion and successfully predicted a feasible region of balance control in the A/P direction based on environmental, anatomical and physiological constraints. They suggested that forward or backward falls would occur when exceeding the torque and state boundaries. Since the movement of the COM is the result of all forces and motions acting on the body segments (Saunders et al., 1953), data on the acceleration of the COM seem to better relate the motion of the COM to the forces applied. Moreover, apart from the A/P direction, mediolateral (M/L) and vertical motions of the COM are also important since the human movements are three-dimensional in nature.

Although stability of the body together with sufficient foot clearance are essential for a successful and safe obstacle-crossing, study of COM motion in young adults during obstacle crossing has been limited (Chou et al. 2001; Hahn and Chou, 2004). Chou et al. (2001) used the range of motion (ROM) and peak velocity of the COM as well as the maximum distance between the COM and COP to investigate the dynamic stability of the body during obstaclecrossing. However, accelerations of the COM were not included. Moreover, although peak velocities and distances, and ROM of the COM motion may help establish a general picture of body stability control during obstacle crossing, COM motion at certain critical times, such as instances of crossing and those at the transition between single and double stance, can provide further important data for the understanding of the control of body stability during successful obstacle crossing. If stability in these instances is not maintained due to some physical-related conditions such as muscle weakness, falls may occur during obstacle crossing.

The aim of this study was to investigate the influence of obstacle height on the three-dimensional motion of the COM, including accelerations, during obstacle crossing in young adults. It is hoped that the results of the study will provide baseline data for future studies on older subjects or patient groups.

\section{MATERIALS AND METHODS}

Ten young adults (age: $26.1 \pm 2.5$ years, height: $174.3 \pm 6.8 \mathrm{~cm}$, weight: $68.7 \pm 8.6 \mathrm{~kg}$, leg length $(\mathrm{LL}): 88.9 \pm 3.6 \mathrm{~cm}$ ) participated in the present study with informed consent. They were all free of neuromusculoskeletal dysfunction and with normal corrected vision. Clearance to conduct the study was provided by the Institutional Human Research Ethics Committee. In a gait laboratory, each subject walked at a self-selected pace and crossed a height-adjustable obstacle made of an aluminum tube placed across a metal frame. Twenty-two infrared retroreflective markers were placed on the body segments. Motions of the body segments were measured with a 7-camera motion analysis system (Vicon512, Oxford Metrics, U.K.). Two additional markers were placed on each end of the tube to define the position of the obstacle. Test conditions included crossing obstacles of three different heights (10, 20 and 30\% LL) for both limbs. LL is defined as the distance between ipsilateral ASIS and medial malleolus. For all conditions, subjects were instructed to walk along the walkway and step over the obstacle. Six trials, three for each side, for each condition were recorded for each subject.

A 12-body-segment model of the whole body with the trunk-head-neck, upper arms, forearm-hands, pelvis, thighs, shanks and feet modeled as rigid bodies was used for COM motion analysis. The position of the COM of the whole body $(\boldsymbol{C})$ was calculated as follows,

$$
\boldsymbol{C}=\frac{\sum_{i=1}^{12} m_{i} \boldsymbol{c}_{i}}{B M},
$$

where $m_{i}$ and $\boldsymbol{c}_{i}$ were the mass and position of the COM of the $i$-th body segment calculated using marker data and Dempster's coefficients (Winter, 1990). BM was the total body mass of the subject. The A/P position of the COM was described relative to the obstacle, a zero value being directly above the obstacle and a positive value being anterior to the obstacle, Fig. 1. The medial-lateral M/L position of the COM was described relative to the line of progression that bisected its ROM, a positive value being to the side of the leading limb, Fig. 1. The vertical position of the COM was described relative to the ground, Fig. 1. Velocities and accelerations of the COM were then calculated by smoothing and differentiation of the COM position trajectories using the generalized cross-validatory spline method (Woltring, 1986).

The crossing cycle was defined as the heel-strike of the trailing limb before crossing the obstacle to the next heel-strike of the same foot after crossing the obstacle. During the complete crossing cycle, the instances when the swing toe was above the obstacle and at the transition between single and double stance (i.e. heel-strike and toe-off) were critical ones at which maintaining body stability became more difficult. Therefore, apart from the ROM of the COM, values 


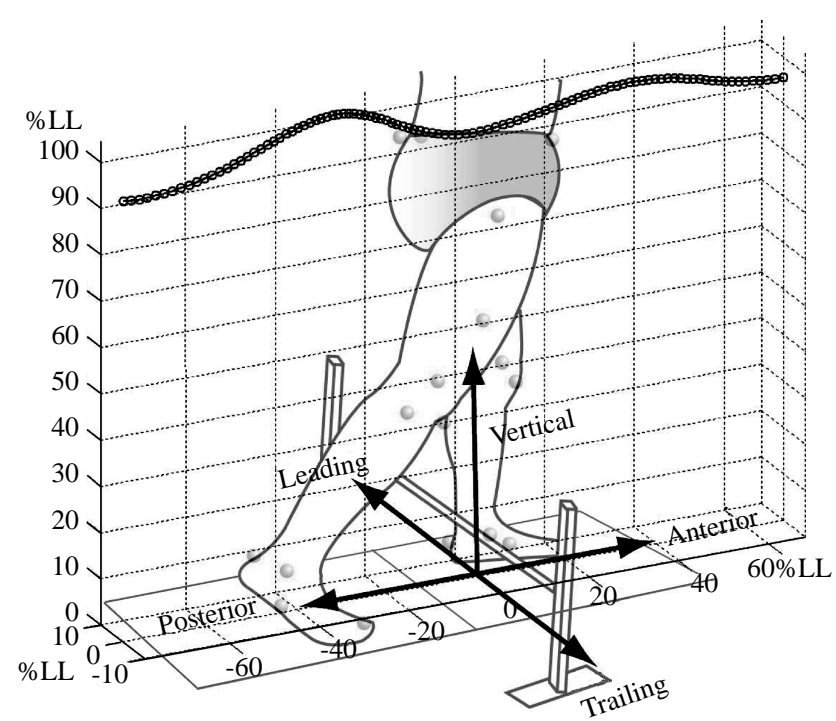

Fig. 1 The reference system used to describe the motion of the body COM during obstacle-crossing. Also shown is a typical three-dimensional trajectory of the COM motion during a crossing cycle.

of curves of the COM motion at these times, including leading toe-off (T1), leading heel-strike (T3), trailing toe-off (T4) and the instance when the swing toe was above the obstacle of both limbs (T2, T5), were extracted for subsequent statistical analysis. The COM-COP distances, defined as the horizontal projection of the COM-COP vector, at these five times were also calculated. For between-subject comparisons, all the above calculated data were normalized to LL (Pai and Patton, 1997). Crossing velocities for all conditions were also calculated. The calculated variables for different obstacle heights were analyzed using repeated measures analysis of variance (RMANOVA) with polynomial test to determine the trend (linear, quadratic). A significant level was set at $\alpha=0.05$. SPSS Version 11.0 (SPSS Inc., Chicago, IL) was used for all statistical analyses.

\section{RESULTS}

The crossing velocity decreased linearly with increasing obstacle height $(10 \%: 0.95 \pm 0.09 \mathrm{~m} / \mathrm{s}$; 20\%: $0.87 \pm 0.08 \mathrm{~m} / \mathrm{s} ; 30 \%: 0.80 \pm 0.08 \mathrm{~m} / \mathrm{s})$. The ensemble-averaged curves of the COM position, velocity and acceleration in the vertical direction during the crossing cycle are shown in Fig. 2. Corresponding data in the $\mathrm{M} / \mathrm{L}$ and $\mathrm{A} / \mathrm{P}$ directions are given in Fig. 3 and Fig. 4, respectively. For each component of the COM motion, similar patterns were found for all obstacle heights, Figs. 2-4. COM position curves in the vertical and M/L directions had two peak values which occurred around the instances when the
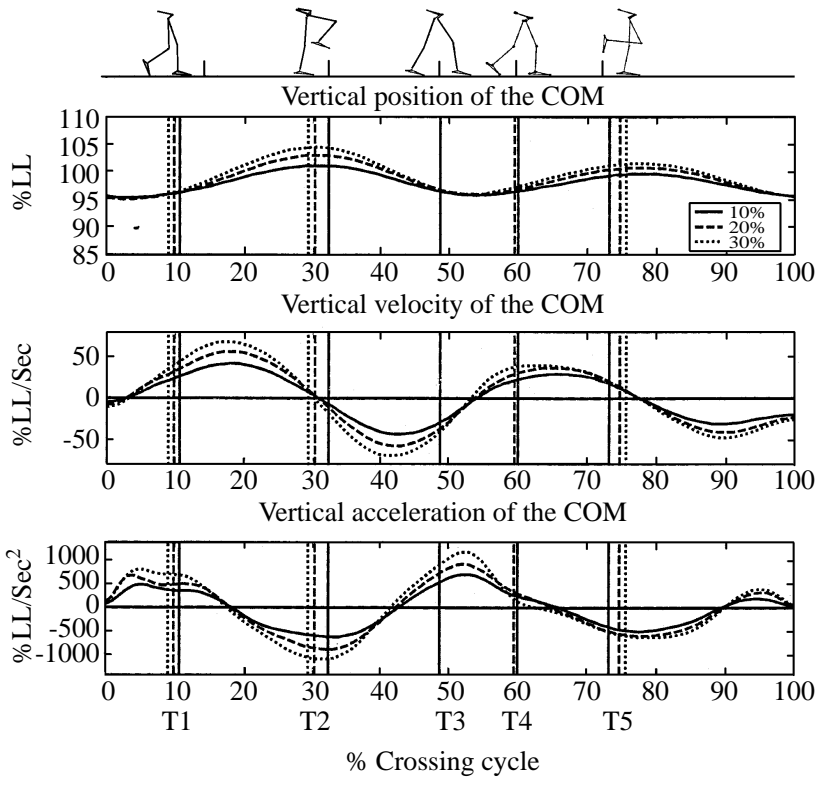

Fig. 2 Ensemble-averaged vertical motion of the COM, including position, velocity and acceleration when crossing obstacles of $10 \%$ LL (solid), 20\%LL (dashed) and 30\%LL (dotted). Vertical lines indicate the critical times (T1: leading toe-off; T2: leading toe above the obstacle; T3: leading heel-strike; T4: trailing toe-off; T5: trailing toe above the obstacle). Stick figures above the curves demonstrate the motions of the locomotor system at critical times during obstacle crossing.
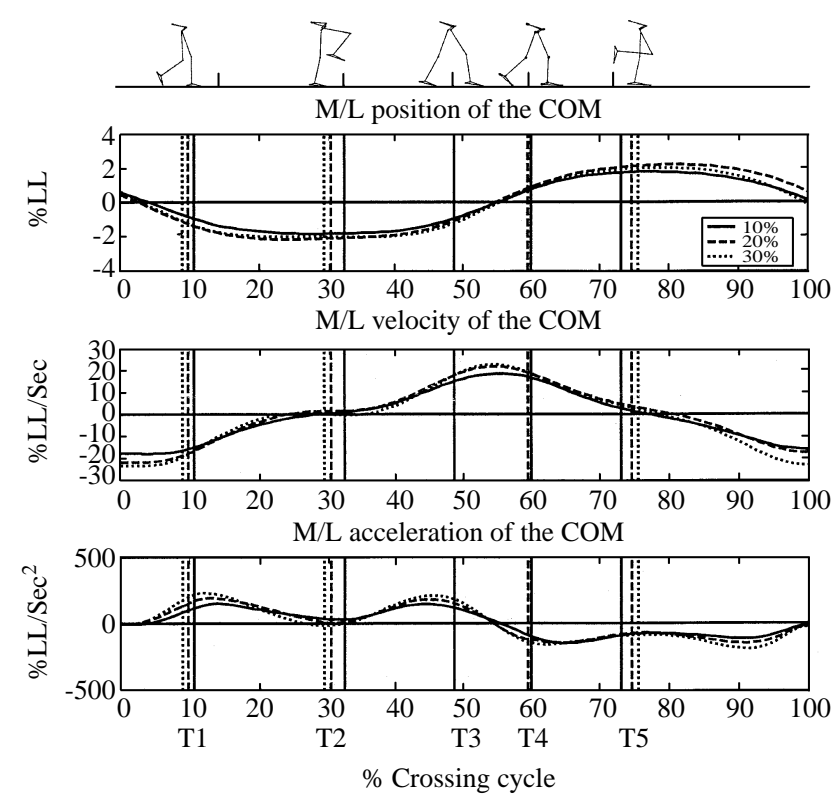

Fig. 3 Ensemble-averaged M/L motion of the COM, including position, velocity and acceleration when crossing obstacles of $10 \%$ LL (solid), 20\%LL (dashed) and 30\%LL (dotted). Vertical lines indicate the critical times (T1: leading toeoff; T2: leading toe above the obstacle; T3: leading heelstrike; T4: trailing toe-off; T5: trailing toe above the obstacle). Stick figures above the curves demonstrate the motions of the locomotor system at critical times during obstacle crossing. 
Table 1 Means (standard deviations) of the vertical COM motion at five critical times. An asterisk indicates significant height effect with linear trend $(p<0.05)$. (T1: leading toe-off; T2: leading toe above the obstacle; T3: leading heel-strike; T4: trailing toe-off; T5: trailing toe above the obstacle)

\begin{tabular}{|c|c|c|c|c|c|c|c|c|c|c|c|}
\hline $\begin{array}{l}\text { COM } \\
\text { motion }\end{array}$ & $\begin{array}{c}\text { Obstacle } \\
\text { height }\end{array}$ & $\mathrm{T} 1$ & & $\mathrm{~T} 2$ & & $\mathrm{~T} 3$ & & $\mathrm{~T} 4$ & & T5 & \\
\hline \multirow{3}{*}{$\begin{array}{l}\text { Position } \\
\text { (\%LL) }\end{array}$} & $10 \%$ & $\begin{array}{l}95.94 \\
(1.52)\end{array}$ & $*$ & $\begin{array}{c}101.08 \\
(1.30)\end{array}$ & $*$ & $\begin{array}{l}96.75 \\
(1.28)\end{array}$ & - & $\begin{array}{l}96.29 \\
(1.22)\end{array}$ & $*$ & $\begin{array}{l}99.18 \\
(1.30)\end{array}$ & $*$ \\
\hline & $20 \%$ & $\begin{array}{l}95.75 \\
(1.58)\end{array}$ & & $\begin{array}{c}102.93 \\
(1.39)\end{array}$ & & $\begin{array}{l}97.05 \\
(1.16)\end{array}$ & & $\begin{array}{l}96.48 \\
(1.18)\end{array}$ & & $\begin{array}{c}100.52 \\
(1.56)\end{array}$ & \\
\hline & $30 \%$ & $\begin{array}{l}95.61 \\
(1.54)\end{array}$ & & $\begin{array}{c}104.32 \\
(0.37)\end{array}$ & & $\begin{array}{l}97.02 \\
(1.06)\end{array}$ & & $\begin{array}{l}96.92 \\
(1.20)\end{array}$ & & $\begin{array}{r}101.36 \\
(1.50)\end{array}$ & \\
\hline \multirow{3}{*}{$\begin{array}{l}\text { Velocity } \\
\text { (\%LL/sec) }\end{array}$} & $10 \%$ & $\begin{array}{l}22.77 \\
(6.25)\end{array}$ & $*$ & $\begin{array}{l}-2.85 \\
(8.51)\end{array}$ & $*$ & $\begin{array}{c}-32.78 \\
(9.34)\end{array}$ & $*$ & $\begin{array}{l}20.42 \\
(7.75)\end{array}$ & $*$ & $\begin{array}{l}20.23 \\
(6.21)\end{array}$ & $*$ \\
\hline & $20 \%$ & $\begin{array}{l}27.96 \\
(6.63)\end{array}$ & & $\begin{array}{c}8.55 \\
(8.33)\end{array}$ & & $\begin{array}{l}-42.93 \\
(10.28)\end{array}$ & & $\begin{array}{l}26.96 \\
(9.73)\end{array}$ & & $\begin{array}{l}18.30 \\
(9.19)\end{array}$ & \\
\hline & $30 \%$ & $\begin{array}{l}27.61 \\
(9.03)\end{array}$ & & $\begin{array}{l}17.47 \\
(7.08)\end{array}$ & & $\begin{array}{c}-48.53 \\
(7.45)\end{array}$ & & $\begin{array}{c}37.76 \\
(10.10)\end{array}$ & & $\begin{array}{l}13.97 \\
(8.62)\end{array}$ & \\
\hline \multirow{3}{*}{$\begin{array}{c}\text { Acceleration } \\
\left(\% \mathrm{LL} / \mathrm{sec}^{2}\right)\end{array}$} & $10 \%$ & $\begin{array}{c}361.62 \\
(161.55)\end{array}$ & $*$ & $\begin{array}{r}-597.72 \\
(99.73)\end{array}$ & $*$ & $\begin{array}{c}437.65 \\
(178.10)\end{array}$ & $*$ & $\begin{array}{c}301.75 \\
(127.93)\end{array}$ & $*$ & $\begin{array}{l}-348.22 \\
(129.32)\end{array}$ & $*$ \\
\hline & $20 \%$ & $\begin{array}{c}494.14 \\
(235.88)\end{array}$ & & $\begin{array}{l}-824.36 \\
(118.75)\end{array}$ & & $\begin{array}{c}595.40 \\
(231.83)\end{array}$ & & $\begin{array}{c}411.77 \\
(193.23)\end{array}$ & & $\begin{array}{l}-501.94 \\
(135.28)\end{array}$ & \\
\hline & $30 \%$ & $\begin{array}{c}725.84 \\
(186.71)\end{array}$ & & $\begin{array}{r}-1006.83 \\
(146.37)\end{array}$ & & $\begin{array}{c}784.45 \\
(267.75)\end{array}$ & & $\begin{array}{c}266.54 \\
(231.88)\end{array}$ & & $\begin{array}{l}-548.44 \\
(117.12)\end{array}$ & \\
\hline
\end{tabular}
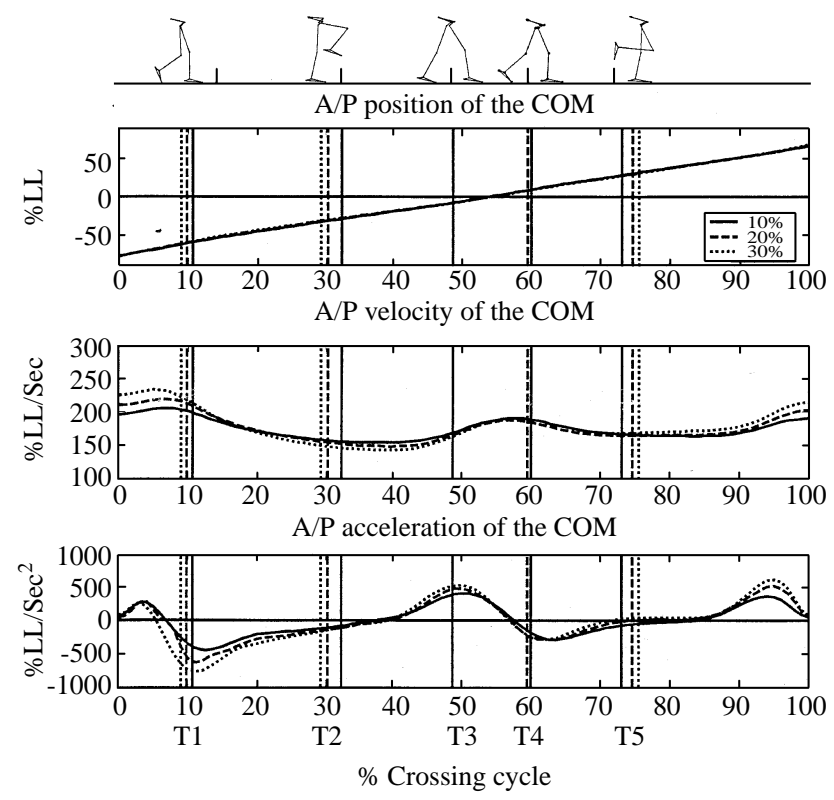

Fig. 4 Ensemble-averaged A/P motion of the COM, including position, velocity and acceleration when crossing obstacles of $10 \%$ LL (solid), 20\%LL (dashed) and 30\%LL (dotted). Vertical lines indicate the critical times (T1: leading toeoff; T2: leading toe above the obstacle; T3: leading heelstrike; T4: trailing toe-off; T5: trailing toe above the obstacle). Stick figures above the curves demonstrate the motions of the locomotor system at critical times during obstacle crossing. swing toe was above the obstacle (T2 and T5, Figs. 2-3). The peak values of the COM velocities and accelerations occurred at different time instances among all the components, Figs. 2-4.

Height effects on the vertical COM motion at critical times are shown in Table 1. Significant height effects on the COM position were found at all critical times except for those at T3 $(p<0.01)$. Vertical position of the COM at T2, T4 and T5 increased linearly but those at $\mathrm{T} 1$ decreased linearly with increasing obstacle height, Table 1. Height effects on the vertical velocity and acceleration of the COM were found at all critical times (velocity: $p<0.02$; acceleration: $p<0.01$; Table 1). Vertical ROMs of the COM were $6.21 \pm 0.79 \% \mathrm{LL}, 8.29 \pm 0.95 \% \mathrm{LL}$ and $9.77 \pm 1.02$ $\%$ LL for $10 \%, 20 \%$ and $30 \%$ obstacles, which increased with increasing obstacle height $(p<0.001)$.

Height effects on the COM motion in the M/L direction at critical times are shown in Table 2. Significant height effect on the COM position was found at T3 $(p=0.02)$. Height effects on the M/L velocity were found at T1 and T3 $(p<0.05)$ while those for the acceleration were found at T1, T2, T3 and T4 ( $p$ $<0.005$, Table 2). M/L ROMs of the COM were not affected by obstacle height. They were $4.74 \pm 1.15$ $\%$ LL, $5.39 \pm 1.52 \% \mathrm{LL}$ and $5.61 \pm 1.30 \% \mathrm{LL}$ for $10 \%$, $20 \%$ and $30 \%$ obstacles, respectively. M/L COMCOP distance at all critical times was not affected by 
Table 2 Means (standard deviations) of the M/L COM motion at five critical times. An asterisk indicates significant height effect with linear trend $(p<0.05)$. (T1: leading toe-off; T2: leading toe above the obstacle; T3: leading heel-strike; T4: trailing toe-off; T5: trailing toe above the obstacle)

\begin{tabular}{|c|c|c|c|c|c|c|c|c|c|c|c|}
\hline $\begin{array}{l}\text { COM } \\
\text { motion }\end{array}$ & $\begin{array}{c}\text { Obstacle } \\
\text { height }\end{array}$ & $\mathrm{T} 1$ & & $\mathrm{~T} 2$ & & T3 & & $\mathrm{T} 4$ & & T5 & \\
\hline \multirow{3}{*}{$\begin{array}{l}\text { Position } \\
(\% \mathrm{LL})\end{array}$} & $10 \%$ & $\begin{array}{l}-0.85 \\
(0.68)\end{array}$ & - & $\begin{array}{l}-1.83 \\
(0.62)\end{array}$ & - & $\begin{array}{l}-1.10 \\
(0.54)\end{array}$ & $*$ & $\begin{array}{c}0.60 \\
(0.55)\end{array}$ & - & $\begin{array}{c}1.67 \\
(0.64)\end{array}$ & - \\
\hline & $20 \%$ & $\begin{array}{l}-1.12 \\
(074)\end{array}$ & & $\begin{array}{l}-2.14 \\
(0.58)\end{array}$ & & $\begin{array}{l}-1.30 \\
(0.52)\end{array}$ & & $\begin{array}{l}0.62 \\
(066)\end{array}$ & & $\begin{array}{l}2.04 \\
(074)\end{array}$ & \\
\hline & $30 \%$ & $\begin{array}{l}-0.94 \\
(1.08)\end{array}$ & & $\begin{array}{l}-2.02 \\
(0.80)\end{array}$ & & $\begin{array}{l}-1.44 \\
(0.58)\end{array}$ & & $\begin{array}{c}0.54 \\
(0.73)\end{array}$ & & $\begin{array}{c}1.96 \\
(0.98)\end{array}$ & \\
\hline \multirow{3}{*}{$\begin{array}{l}\text { Velocity } \\
\text { (\%LL/sec) }\end{array}$} & $10 \%$ & $\begin{array}{r}-15.86 \\
(5.59)\end{array}$ & $*$ & $\begin{array}{c}0.68 \\
(3.69)\end{array}$ & - & $\begin{array}{l}14.14 \\
(4.84)\end{array}$ & $*$ & $\begin{array}{l}17.50 \\
(4.34)\end{array}$ & - & $\begin{array}{c}3.30 \\
(4.63)\end{array}$ & - \\
\hline & $20 \%$ & $\begin{array}{r}-18.98 \\
(4.13)\end{array}$ & & $\begin{array}{c}1.30 \\
(3.96)\end{array}$ & & $\begin{array}{l}16.50 \\
(5.70)\end{array}$ & & $\begin{array}{l}20.37 \\
(5.54)\end{array}$ & & $\begin{array}{c}4.22 \\
(3.49)\end{array}$ & \\
\hline & $30 \%$ & $\begin{array}{r}-20.66 \\
(5.61)\end{array}$ & & $\begin{array}{c}0.12 \\
(4.85)\end{array}$ & & $\begin{array}{l}16.63 \\
(4.86)\end{array}$ & & $\begin{array}{l}20.24 \\
(5.69)\end{array}$ & & $\begin{array}{c}2.89 \\
(2.93)\end{array}$ & \\
\hline \multirow{3}{*}{$\begin{array}{l}\text { Acceleration } \\
\left(\% \mathrm{LL} / \mathrm{sec}^{2}\right)\end{array}$} & $10 \%$ & $\begin{array}{c}97.67 \\
(61.90)\end{array}$ & $*$ & $\begin{array}{c}27.31 \\
(27.77)\end{array}$ & $*$ & $\begin{array}{l}130.21 \\
(38.30)\end{array}$ & $*$ & $\begin{array}{l}-80.79 \\
(35.74)\end{array}$ & $*$ & $\begin{array}{l}-94.39 \\
(28.19)\end{array}$ & - \\
\hline & $20 \%$ & $\begin{array}{l}128.72 \\
(57.20)\end{array}$ & & $\begin{array}{c}10.47 \\
(28.27)\end{array}$ & & $\begin{array}{l}173.14 \\
(53.59)\end{array}$ & & $\begin{array}{r}-110.80 \\
(78.73)\end{array}$ & & $\begin{array}{l}-75.91 \\
(33.96)\end{array}$ & \\
\hline & $30 \%$ & $\begin{array}{l}146.49 \\
(77.99)\end{array}$ & & $\begin{array}{l}-15.37 \\
(43.48)\end{array}$ & & $\begin{array}{l}203.98 \\
(48.55)\end{array}$ & & $\begin{array}{r}-125.13 \\
(59.88)\end{array}$ & & $\begin{array}{l}-89.26 \\
(33.99)\end{array}$ & \\
\hline \multirow{3}{*}{$\begin{array}{c}\text { COM-COP } \\
\text { Distance } \\
(\% \mathrm{LL})\end{array}$} & $10 \%$ & $\begin{array}{c}6.32 \\
(1.78)\end{array}$ & - & $\begin{array}{c}6.47 \\
(1.59)\end{array}$ & - & $\begin{array}{c}7.46 \\
(2.02)\end{array}$ & - & $\begin{array}{l}-6.97 \\
(1.54)\end{array}$ & - & $\begin{array}{l}-6.56 \\
(1.59)\end{array}$ & - \\
\hline & $20 \%$ & $\begin{array}{c}6.73 \\
(1.23)\end{array}$ & & $\begin{array}{c}6.66 \\
(1.16)\end{array}$ & & $\begin{array}{c}7.82 \\
(1.81)\end{array}$ & & $\begin{array}{l}-7.35 \\
(1.92)\end{array}$ & & $\begin{array}{l}-6.74 \\
(1.76)\end{array}$ & \\
\hline & $30 \%$ & $\begin{array}{c}6.22 \\
(1.41)\end{array}$ & & $\begin{array}{c}6.12 \\
(1.65)\end{array}$ & & $\begin{array}{c}7.51 \\
(1.81)\end{array}$ & & $\begin{array}{l}-7.57 \\
(1.72)\end{array}$ & & $\begin{array}{l}-6.82 \\
(1.74)\end{array}$ & \\
\hline
\end{tabular}

obstacle height ( $p>0.05$, Table 2).

Height effects on the COM motion in the A/P direction at critical times are shown in Table 3. For the A/P position of the COM, a linearly decreased trend was detected at $\mathrm{T} 2$ with increasing obstacle height $(p=0.01$, Table 3$)$. At T1 anterior velocity of the COM increased linearly with increasing obstacle height $(p<0.001$, Table 3 ). Height effects on the $\mathrm{A} / \mathrm{P}$ acceleration of the $\mathrm{COM}$ were found at all critical times except at T4 $(p<0.03$, Table 3$)$. A/P ROMs of the COM were $144.96 \pm 6.92 \% \mathrm{LL}, 145.70 \pm 6.72$ $\%$ LL and $147.26 \pm 8.31 \% \mathrm{LL}$ for $10 \%, 20 \%$ and $30 \%$ obstacles, respectively. The results showed that $\mathrm{A} / \mathrm{P}$ ROMs of the COM were not affected by obstacle height $(\mathrm{p}>0.05)$. Height effects on the A/P COMCOP distance were found at T1, T2 and T5 $(p<$ 0.001, Table 3).

\section{DISCUSSION}

Dynamic stability of the body in terms of the 3D motion of the COM is important for successful and safe obstacle crossing. The purpose of the present study was to investigate the body dynamic stability in terms of positions, velocities and accelerations of the COM as well as the COM and COP interactions in young adults when crossing obstacles of different heights. It is hoped that the results of the study will provide baseline data for future studies on older subjects or patient groups.

The ROM of the COM represented the overall stability of the body during obstacle crossing. The ROM of the COM in the vertical direction increased with increasing obstacle height while those in the $\mathrm{A} / \mathrm{P}$ and $\mathrm{M} / \mathrm{L}$ directions were not affected by obstacle height (Tables 1-3), suggesting that the COM excursion in the vertical direction was more sensitive to the change of obstacle height than those in the other two directions. Similar results were also found in the literature (Chou et al., 2001). Apart from the position of the COM in the vertical direction, velocity and acceleration in this direction also exhibited significant height effects at all critical times. Chou et al. (2001) reported that greater peak velocity of the COM in the vertical direction was needed for higher obstacles. Increasing the height of the obstacle increases directly the challenge to the control of the stability in the vertical direction during obstacle 
Table 3 Means (standard deviations) of the A/P COM motion at five critical times. An asterisk indicates significant height effect with linear trend $(p<0.05)$. (T1: leading toe-off; T2: leading toe above the obstacle; T3: leading heel-strike; T4: trailing toe-off; T5: trailing toe above the obstacle)

\begin{tabular}{|c|c|c|c|c|c|c|c|c|c|c|c|}
\hline $\begin{array}{l}\text { COM } \\
\text { motion }\end{array}$ & $\begin{array}{c}\text { Obstacle } \\
\text { height }\end{array}$ & $\mathrm{T} 1$ & & $\mathrm{~T} 2$ & & $\mathrm{~T} 3$ & & $\mathrm{~T} 4$ & & $\mathrm{~T} 5$ & \\
\hline \multirow{5}{*}{$\begin{array}{l}\text { Position } \\
(\% \text { LL) }\end{array}$} & $10 \%$ & $\begin{array}{c}-61.74 \\
(4.33)\end{array}$ & \multirow[t]{5}{*}{-} & $\begin{array}{r}-30.67 \\
(2.84)\end{array}$ & \multirow[t]{5}{*}{$*$} & $\begin{array}{l}-9.41 \\
(3.16)\end{array}$ & - & $\begin{array}{c}8.13 \\
(3.41)\end{array}$ & \multirow[t]{5}{*}{-} & $\begin{array}{l}27.30 \\
(3.98)\end{array}$ & \multirow[t]{5}{*}{-} \\
\hline & $20 \%$ & -62.59 & & -32.05 & & -9.19 & & 7.16 & & 28.82 & \\
\hline & & (4.17) & & (2.96) & & $(1.96)$ & & $(2.56)$ & & $(1.73)$ & \\
\hline & $30 \%$ & -63.73 & & -33.28 & & -9.64 & & 6.74 & & 29.50 & \\
\hline & & $(3.82)$ & & (2.99) & & (1.55) & & (1.95) & & $(2.20)$ & \\
\hline \multirow{6}{*}{$\begin{array}{l}\text { Velocity } \\
\text { (\%LL/sec) }\end{array}$} & $10 \%$ & 201.57 & \multirow[t]{6}{*}{$*$} & 155.97 & \multirow[t]{6}{*}{-} & 161.13 & - & 191.60 & \multirow[t]{6}{*}{-} & 167.84 & \multirow[t]{6}{*}{-} \\
\hline & & (11.90) & & (11.74) & & $(11.74)$ & & $(8.11)$ & & $(7.33)$ & \\
\hline & $20 \%$ & 216.18 & & 154.90 & & 161.71 & & 189.65 & & 164.71 & \\
\hline & & $(9.72)$ & & (11.79) & & (8.96) & & (8.64) & & (10.06) & \\
\hline & $30 \%$ & 227.19 & & 150.76 & & 159.88 & & 188.82 & & 168.96 & \\
\hline & & $(15.79)$ & & $(14.44)$ & & (11.96) & & $(9.58)$ & & $(11.70)$ & \\
\hline \multirow{6}{*}{$\begin{array}{l}\text { Acceleration } \\
\left(\% \mathrm{LL} / \mathrm{sec}^{2}\right)\end{array}$} & $10 \%$ & -331.94 & \multirow[t]{6}{*}{$*$} & -101.54 & \multirow[t]{6}{*}{$*$} & 372.07 & \multirow[t]{6}{*}{$*$} & -146.26 & & -92.34 & \multirow[t]{6}{*}{ * } \\
\hline & & (107.33) & & $(75.32)$ & & (110.07) & & $(121.86)$ & & $(77.75)$ & \\
\hline & $20 \%$ & -384.0 & & -158.56 & & 467.95 & & -133.68 & & -3.70 & \\
\hline & & $(247.18)$ & & (68.09) & & $(133.15)$ & & $(166.11)$ & & $(71.54)$ & \\
\hline & $30 \%$ & -492.46 & & -185.90 & & 528.94 & & -147.78 & & 41.16 & \\
\hline & & $(214.02)$ & & $(76.89)$ & & $(156.48)$ & & $(156.04)$ & & $(60.24)$ & \\
\hline \multirow{6}{*}{$\begin{array}{c}\text { COM-COP } \\
\text { Distance } \\
(\% \mathrm{LL})\end{array}$} & $10 \%$ & -20.11 & \multirow[t]{6}{*}{$*$} & 1.90 & \multirow[t]{6}{*}{$*$} & 18.10 & \multirow[t]{6}{*}{-} & -21.66 & \multirow[t]{6}{*}{-} & -6.69 & \multirow[t]{6}{*}{$*$} \\
\hline & & (2.16) & & $(2.01)$ & & $(1.70)$ & & $(2.63)$ & & (1.42) & \\
\hline & $20 \%$ & -22.12 & & 0.53 & & 17.99 & & -22.70 & & -5.03 & \\
\hline & & (2.51) & & (1.89) & & $(1.55)$ & & $(2.27)$ & & (1.72) & \\
\hline & $30 \%$ & -23.44 & & -0.40 & & 17.96 & & -22.80 & & -3.97 & \\
\hline & & $(3.55)$ & & $(2.22)$ & & $(2.02)$ & & $(2.56)$ & & $(1.40)$ & \\
\hline
\end{tabular}

crossing. Therefore, the young adults needed to elevate their COM more to maintain sufficient foot clearance to cross higher obstacles, resulting in significant changes in the vertical velocity and acceleration of the COM.

When the swing toe was above the obstacle (T2 and T5), significantly higher vertical positions of the COM were adopted by the young subjects when facing higher obstacles, Fig. 2 and Table 1. Significant height effects on the COM positions were also found at toe-off for both limbs (T1 and T4), indicating that there was anticipatory adjustment of the position of the COM to avoid tripping over obstacles. To accommodate the changes in the vertical positions of the COM with increasing obstacle height, vertical velocities and accelerations of the COM were also modulated at all critical times (T1-T5). At toe-off (T1 or T4), different height effects on the COM motion were found between the leading and trailing limbs. At leading toe-off (T1), the vertical position of the COM decreased with increasing obstacle height and with increased vertical velocity and acceleration. This increased acceleration and thus increased elevated force at $\mathrm{T} 1$ may be responsible for the increased vertical position of the COM at T2. At trailing toe-off (T4), on the other hand, the vertical acceleration of the COM decreased with increasing obstacle height but the vertical height of the COM at T5 was increased, most likely due to different postural demands between T2 and T5. Since the COM had increased the height of the vertical position and vertical velocity with increasing obstacle height at T4, less elevated force and thus less acceleration were needed to push the COM upward. When the swing toe was above the obstacle (T2 and T5), vertical decelerations of the COM suggest that braking forces acting at the COM were used to slow down the motion. When facing higher obstacles, vertical deceleration of the COM was increased, indicating that greater braking forces were needed to maintain the necessary stability for higher COM positions. Since the COM position during leading limb crossing was higher than that during trailing limb crossing, greater deceleration and thus greater braking force were needed at $\mathrm{T} 2$, indicating that more muscular demand was needed for maintaining vertical stability when the leading toe was above the 
obstacle. Chen and Lu (2006) also reported that more muscular efforts were needed in the trailing stance limb to maintain stability when the leading toe was above the obstacle. If the muscular demand can not be met, such as in the elderly, falls due to tripping over obstacles may occur. It seems that vertical components of the COM motion, including position, velocity and acceleration, were all modulated to successfully cross obstacles of different height and that these modulations were different between the leading and trailing limbs.

Compared to the vertical direction, the COM position and velocity in the M/L directions were found to be less affected by obstacle height, in agreement with Chou et al. (2001). Significant height effect on the M/L COM position was present only at T3 and velocity at T1 and T3. However, height effect on the acceleration in the $\mathrm{M} / \mathrm{L}$ direction was significant at T1, T2, T3 and T4, Table 2. This suggests that the COM acceleration may be more sensitive to height changes than the COM position and velocity in the $\mathrm{M} / \mathrm{L}$ direction. At T1, COM M/L velocity increased with obstacle height so increased M/L deceleration was needed to ensure smoother transfer of the COM to the other stance limb. Similar to T1, increased $\mathrm{M} / \mathrm{L}$ deceleration of the COM at T4 was also used to slow down the M/L COM motion for better stability control. Among the five critical instances, T3 is the only one at which the M/L COM position, velocity and acceleration were all affected by obstacle heights. Together with the finding that the maximum COMCOP distance occurred at T3, this suggests that the control of the M/L stability at T3 may be more difficult than at other instances with increasing obstacle height. Since maintaining stability can be fulfilled by minimizing motions of the COM relative to COP, bigger COM-COP distances at T3 indicated that more effort was required for controlling the COM motion. When obstacle height increased, M/L position of the COM at T3 was farther from the leading stance limb but velocity and acceleration of the COM towards the leading stance limb was increased linearly to bring the COM close to the leading base of support, Fig. 3 and Table 2. Since the acceleration of the COM is directly related to the forces applied to the COM, the increase in the magnitude of the $\mathrm{M} / \mathrm{L}$ acceleration of the COM with increasing obstacle height suggests that increased forces from muscle contractions are required to ensure the control of the smooth transition of the COM position between single and double stance phase. Therefore, if the M/L stability is compromised such as due to muscle weakness or degradation of coordination, falls may occur.

COM acceleration was also more sensitive to the obstacle height than velocity and position in the $\mathrm{A} / \mathrm{P}$ direction. When the leading toe was above the obstacle (T2), a more posterior COM position was adopted to decrease the A/P COM-COP distance with increasing obstacle height, which seemed to be a useful strategy to ensure sufficient stability when facing higher challenges, Fig.4 and Table 3. At the same time, increased A/P deceleration of the COM was needed to slow down the COM motion with increasing obstacle height. At T5, the A/P acceleration and COM-COP distance were affected by the obstacle height but the $\mathrm{A} / \mathrm{P}$ position of the $\mathrm{COM}$ was not. At the instance, A/P decelerations of the COM were decreased with increasing obstacle height and became acceleration at the $30 \%$ height, suggesting that increased anterior propulsive forces were required for higher obstacles. Comparing COM accelerations at $\mathrm{T} 2$ and T5, it was found that different strategies adopted by the leading and trailing limbs should result from the distinct mechanical demand of each limb. When the leading toe was above the obstacle, the COM was moving away from the supporting trailing limb so the deceleration of the COM provided by a braking force was required to maintain sufficient stability. On the other hand, the COM had to move towards the BOS (leading foot) when the trailing limb was crossing. For this purpose, a propulsion force was needed, resulting in apparent decreased A/P COM-COP distance with increasing obstacle height. At T1, unchanged position of the COM, and increased COM velocity and deceleration in the $\mathrm{A} / \mathrm{P}$ direction were found with increasing obstacle height, indicating that increased braking forces were used to keep the COM position unchanged with increased velocity. This strategy was adopted to ensure a smooth transfer of body weight to the other stance limb with sufficient stability. At T3, maximum A/P COM-COP distance suggested that the control of the A/P stability may be more difficult, thus increased A/P acceleration of the COM was needed with increasing obstacle height. From the above discussion, it is suggested that whole body control through the adjustments of the $\mathrm{A} / \mathrm{P}$ acceleration of the COM to reduce A/P COM-COP distances was required for the necessary stability in the sagittal plane when crossing obstacles of increased height.

It is noted that with increasing obstacle height a decrease of crossing velocity was accompanied with the above mentioned biomechanical strategies. This indicates that changes of the control of the COM motion when crossing obstacles of different height may be affected by multiple factors. However, further study is necessary to clarify whether the change of crossing velocity is a result of the change of the control strategy or is the main control variable.

\section{CONCLUSIONS}

A successful and safe obstacle-crossing requires 
not only sufficient foot clearance of the swing limb but also the stability of the body provided mainly by the stance limb. Knowledge of the COM motion is useful for understanding the stability during obstacle crossing. Increasing the height of the obstacle increases directly the challenge to the control of the stability in the vertical direction. Therefore, it was found that vertical components of the COM motion, including position, velocity and acceleration, were all modulated to successfully cross obstacles of different height and that these modulations were different between the leading and trailing limbs. Since the acceleration of the COM is directly related to the forces applied to the COM, the increase in the magnitude of the $\mathrm{M} / \mathrm{L}$ acceleration of the COM with increasing obstacle height suggests that increased forces from muscle contractions are required to ensure the control of the smooth transition of the COM position between single and double stance phase. If the M/L stability is compromised, due to muscle weakness or degradation of coordination, falls may occur. Whole body control through adjustments of the A/P acceleration of the COM to reduce A/P COM-COP distances was required for the necessary stability in the sagittal plane when crossing obstacles of increased height. The results from young adults can be used as baseline data in the evaluation of patients and older people, which will be helpful for the design of fallprevention devices and for the planning of rehabilitative interventions.

\section{ACKNOWLEDGMENTS}

Tthe authors gratefully acknowledge the support from the National Science Council (NSC96-2320B002-023) and National Health Research Institutes (NHRI-EX91-9126EP) of Taiwan.

\section{REFERENCES}

Austin, G. P., Garrett, G. E., and Bohannon, R. W., 1999, "Kinematic Analysis of Obstacle Clearance During Locomotion," Gait and Posture, Vol. 10, Is. 2, pp. 109-120.

Begg, R. K., Sparrow, W. A., and Lythgo, N. D., 1998, "Time-Domain Analysis of Foot-Ground Reaction Forces in Negotiating Obstacles," Gait and Posture, Vol. 7, Is. 2, pp. 99-109.

Blake, A. J., Morgan, K., Bendall, M. J., Dallosso, H., Ebrahim, S. B., Arie, T. H., Fentem, P. H., and Bassey, E. J., 1988, "Falls by Elderly People at Home: Prevalence and Associated Factors," Age and Ageing, Vol. 17, No. 6, pp. 365-372.

Campbell, A. J., Borrie, M. J., Spears, G. F., Jackson, S. L., Brown, J. S., and Fitzgerald, J. L., 1990, "Circumstances and Consequences of Falls
Experienced by a Community Population 70 Years and Over during a Prospective Study," Age and Ageing, Vol. 19, No. 2, pp. 136-141.

Chen, H. L., and Lu, T. W., 2006, "Comparisons of the Joint Moments between Leading and Trailing Limb in Young Adults when Stepping over Obstacles," Gait and Posture, Vol. 23, Is. 1, pp. 69-77.

Chou, L. S., and Draganich, L. F., 1997, "Stepping over an Obstacle Increases the Motions and Moments of the Joints of the Trailing Limb in Young Adults," Journal of Biomechanics, Vol. 30, Is. 4, pp. 331-337.

Chou, L. S., and Draganich, L. F., 1998, "Increasing Obstacle Height and Decreasing Toe-Obstacle Distance Affect the Joint Moments of the Stance Limb Differently when Stepping over an Obstacle," Gait and Posture, Vol. 8, Is. 3, pp. 186-204.

Chou, L. S., and Draganich, L. F., 1998, "Placing the Trailing Foot Closer to an Obstacle Reduces Flexion of the Hip, Knee, and Ankle to Increase the Risk of Tripping," Journal of Biomechanics, Vol. 31, Is. 4, pp. 685-691.

Chou, L. S., Kaufman, K. R., Brey, R. H., and Draganich, L. F., 2001, "Motion of the Whole Body's Mass when Stepping over Obstacles of Different Heights," Gait and Posture, Vol. 13, Is. 1, pp. 17-26.

Hahn, M. E., and Chou, L. S., 2004, "Age-Related Reduction in Sagittal Plane Center of Mass Motion During Obstacle Crossing," Journal of Biomechanics, Vol. 37, Is. 6, pp. 837-844.

Collins, J. J., and Luca, C. J. D., 1993, "Open-Loop and Close-Loop Control of Posture: A Random-Walk Analysis of Center-Of-Pressure Trajectories," Experimental Brain Research, Vol. 95, No. 2, pp. 308-318.

Goldie, P. A., Bach, T. M., and Evans, O. M., 1989, "Force Platform Measures for Evaluating Postural Control: Reliability and Validity," Archives of Physical Medicine and Rehabilitation, Vol. 70, No. 7, pp. 510-517.

Kuo, A. D., 1995, "An Optimal Control Model for Analyzing Human Posture Balance," IEEE Transactions on Biomedical Engineering, Vol. 42, No. 1, pp. 87-101.

Overstall, P. W., Exton-Smith, A. N., Imms, F. J., and Johnson, A. L., 1977, "Falls in the Elderly Related to Postural Imbalance," British Medical Journal, Vol. 1, No. 6056, pp. 261-264.

Pai, Y. C., Naughton, B. J., Chang, R. W., and Rogers, M. W., 1994, "Control of Body Center Mass Momentum during Sit-To-Stand among Young and Elderly Adults," Gait and Posture, Vol. 2, Is. 2, pp. 109-116.

Pai, Y. C., and Patton, J., 1997, "Center of Mass Velocity-Position Predictions for Balance Control," 
Journal of Biomechanics, Vol. 30, Is. 4, pp. $347-$ 354.

Patla, A. E., Frank, J. S., and Winter, D. A., 1990, “Assessment of Balance Control in the Elderly: Major issues.," Physiotherapy Canada, Vol. 42, pp. 89-97.

Patla, A. E., Prentice, S. D., Robinson, C., and Neufeld, J., 1991, "Visual Control of Locomotion: Strategies for Changing Direction and for Going over Obstacles," Journal of Experimental Psychology: Human Perception and Performance, Vol. 17, Is. 3, pp. 603-634.

Patla, A. E., and Rietdyk, S., 1993, "Visual Control of Limb Trajectory over Obstacles during Locomotion: Effect of Obstacle Height and Width," Gait and Posture, Vol. 1, Is. 1, pp. 45-60.

Patla, A. E., and Prentice, S. D., 1995, "The Role of Active Forces and Intersegmental Dynamics in the Control of Limb Trajectory over Obstacles during Locomotion in Humans," Experimental Brain Research, Vol. 106, No. 3, pp. 499-504.

Patla, A. E., Rietdyk, S., Martin, C., and Prentice, S., 1996, "Locomotor Patterns of the Leading and the Trailing Limbs as Solid and Fragile Obstacles are Stepped over: Some Insights into the Role of Vision during Locomotion," Journal of Motor Behavior,
Vol. 28, Is. 1, pp. 35-47.

Saunders, J. B., Inman, V. T., and EBerhart, H. D., 1953, "The Major Determinants in Normal and Pathological Gait," Journal of Bone and Joint Surgery, Vol. 35A, Is. 3, pp. 543-558.

Sparrow, W. A., Shinkfield, A. J., Chow, S., and Begg, R. K., 1996, "Characteristics of Gait in Stepping over Obstacles," Human Movement Science, Vol. 15, Is. 4, pp. 605-622.

Tinetti, M. E., and Speechley, M., 1989, "Prevention of Falls among the Elderly," New England Journal of Medicine, Vol. 320, No. 16, pp. 1055-1059.

Winter, D. A., 1990, "Biomechanics and Motor Control of Human Movement," New York, USA.

Winter, D. A., 1995, "Anatomy, Biomechanics and Control of Balance During Standing and Walking," Waterloo Biomechanics, Waterloo, Ontario, Canada.

Woltring, H. J., 1986, “A FORTRAN Package for Generalized, Cross-Validatory Spline Smoothing and Differentiation," Advances in Engineering Software, Vol. 8, No. 2, pp. 104-113.

Manuscript Received: May 15, 2006 Revision Received: Nov. 15, 2006 and Accepted: Dec. 15, 2006 